\title{
Ibuprofen can mask symptoms of infection and might worsen outcomes, says European drugs agency
}

\author{
Ingrid Torjesen
}

London

The European Medicines Agency's pharmacovigilance risk assessment committee (PRAC) has recommended updating the product information for drugs containing ibuprofen and ketoprofen to warn that they can mask the symptoms of infection.

Such masking can delay treatment and worsen outcomes and has been observed in bacterial community acquired pneumonia and bacterial complications to varicella (chickenpox), the committee said after its monthly meeting on 17 April. Patients should therefore be monitored for worsening of infection when drugs containing ibuprofen and ketoprofen are used for relieving fever or pain from an infection.

The committee's recommendation further fuels concerns about ibuprofen, which several UK agencies said last week could be used for treating symptoms of covid-19. ${ }^{1}$ The Medicines and Healthcare Products Regulatory Agency (MHRA), NHS England, and the National Institute for Health and Care Excellence previously recommended that paracetamol be used in preference to ibuprofen for symptoms of covid-19. ${ }^{2}$ But last week they said that ibuprofen could be used in the same way as paracetamol after the Commission on Human Medicines found that there was insufficient evidence to establish a link between ibuprofen or other non-steroidal anti-inflammatory drugs (NSAIDs) and contracting or worsening covid-19.

A spokesperson from the MHRA said: "The PRAC recommendation will lead to updates to the product information for ibuprofen and ketoprofen in the UK so that the products have consistent warnings about the potential for NSAIDs to mask symptoms of bacterial infection." Some drugs containing ibuprofen already have a warning in their product information, the MHRA pointed out. "The regulatory position in relation to use of ibuprofen in its authorised indications (which include possible symptoms of infection such as feverishness) remains unchanged," the spokesperson said.
PRAC's latest recommendations were made after a review of the safety of the drugs containing ibuprofen and ketoprofen, which began in May 2019. The review was prompted by the findings of a survey by the French National Agency for Medicines and Health Products Safety, which suggested that infection with varicella and some bacterial infections could be made worse by these drugs. ${ }^{3}$ The committee reviewed data in the literature, analysed spontaneous reports, and consulted with relevant experts at the European Medicines Agency.

The use of ibuprofen in patients with covid-19 was not assessed in this review, as no data were available. The EMA said that it was monitoring the situation closely and that it would analyse any data on potential adverse effects of NSAIDs in patients with covid-19 as they became available, including data from epidemiological studies.

Paul Little, professor of primary care research at the University of Southampton, said that he thought the European Medicines Agency was "being very sensible" and he agreed with "their take on the evidence." He told The BMJ, "There is enough observational evidence let alone some trial evidence to be cautious about these drugs for acute infections. Whether it is just masking symptoms or whether it is due to other effects of ibuprofen (or both) is still unclear."

Torjesen I. Covid-19: ibuprofen can be used for symptoms, says UK agency, but reasons
for change in advice are unclear. BMJ 2020;369:m1555. 10.1136/bmj.m1555 32303505
Torjesen I. Covid-19: NICE advises against using NSAIDs for fever in patients with
suspected cases. BMJ 2020;369:m1409. . 10.1136/bmj.m1409 32253225
L'Agence Nationale de Sécurité du Médicament et des Produits de Santé.
Anti-inflammatoires non stéroïdiens (AINS) et complications infectieuses graves. Point
d'Information. 18 April 2019. https://www.ansm.sante.fr/S-informer/Points-d-information-
Points-d-information/Anti-inflammatoires-non-steroidiens-AINS-et-complications-
infectieuses-graves-Point-d-Information 